\title{
Closed Fracture of Metacarpal Bone
}

National Cancer Institute

\section{Source}

National Cancer Institute. Closed Fracture of Metacarpal Bone. NCI Thesaurus. Code C35232.

A traumatic break in one or more of the metacarpal bones that does not involve a break in the adjacent skin. 